\title{
La epidemia de cólera de 1834 en Madrid. Asistencia y represión a las clases populares
}

\author{
FLoRentina Vidal Galache
}

Las epidemias de cólera padecidas en España durante el siglo XIX han sido estudiadas por varios autores ${ }^{1}$. En este pequeño trabajo no quiero volver sobre estos aspectos ya conocidos, pero sí resaltar la incidencia negativa que la epidemia de 1834 tuvo, especialmente sobre las clases populares madrileñas. También señalar cómo resulta más clara la actitud represiva o caritativa de la sociedad hacia los marginados, en estos momentos de crisis, en los que, como veremos, confluyen problemas políticos, económicos y el miedo a la enfermedad desconocida hasta entonces.

Los primeros casos de cólera morbo en España se dieron en Vigo en la primavera de 1833. Las tropas conjuntas contendientes en la Guerra de Sucesión portuguesa, que desembarcaron en dicha ciudad, parece fueron las responsables de su llegada a nuestro país, siendo en Andalucía donde se produjeron los casos más violentos en el verano de ese mismo año. Durante el invierno la epidemia quedó en suspenso. A Ma-

' Para más información sobre el cólera en España consultar: M. y J. L. PESET: Muerte en España. Madrid 1972; A. Fernandez Garcia: Repercusiones sociales de las epidemias de cólera del siglo XIX. V Congreso Nacional de Historia de la Medicina. V. I, págs. 127154; F. J. Puerto y C. SAN Juan: «La epidemia de cólera de 1834 en Madrid». Estudios de Historia Social núm. IV. 1980; J. R. DE UROUIJo: "Condiciones de vida y Cólera: la epidemia de 1854-56 en Madrid". Estudios de Historia Social núm. IV. 1980; M. GonzÁlez de Samano: Memoria Histórica del cólera morbo. Madrid 1958. 
drid no llegó hasta el verano de 1834 , siendo en el mes de julio cuando se registraron mayor número de casos.

Durante los años anteriores a la llegada del cólera a la península, desde que la epidemia llegó a Inglaterra en 1832, existía la preocupación por conocer el origen, prevención y tratamiento de esta terrible enfermedad. Numerosos informes, nacionales y extranjeros dieron a los médicos españoles noticias sobre las teorías existentes en el momento ${ }^{2}$. Pero siendo desconocida la etiología de la enfermedad, todos los planes preventivos o curativos no pasaban de meros ensayos a ciegas.

Basándose en los informes y trabajos médicos e higiénicos ya citados, se tomaron una serie de medidas preventivas a nivel local, como cordones sanitarios para evitar el contagio, medidas higiénicas y planes concretos para preparar hospitales donde atender a los enfermos en caso de que llegara la epidemia. Para llevar a efecto todas estas medidas y planes se creó en abril de 1832 la Junta de Sanidad de Madrid, que una vez concretado todo lo que se debía hacer y en vista de que la epidemia no llegaba a la capital quedó en suspenso en marzo de 1833, volviendo a actuar en marzo de 1834, cuando de nuevo se tenían fundados temores de que la epidemia llegara a la capital.

La situación política en el país a principios de verano de 1834 era especialmente conflictiva. A la muerte de Fernando VII, la sucesión al trono había dado lugar a la primera Guerra Carlista y mientras ésta se desarrollaba en el norte, los partidarios de Isabel II y de la regencia de M. ${ }^{a}$ Cristina, convocaron Cortes Generales para finales de julio en Madrid, con la intención de que la sucesión quedara definitivamente legalizada. La inestabilidad vivida en los meses que siguieron a la muerte de Fernando VII hacian temer a los isabelinos que sus enemigos no consentirian la celebración de las esperadas Cortes.

A principios de julio se registraron los primeros casos de cólera en Madrid. Durante los diez primeros días del mes, en la prensa madrileña la situación real se disimuló, no informando de todos los partes diarios

${ }^{2}$ M. SeOANE: Documentos sobre la enfermedad llamada cólera espasmódico de la india... Madrid 1831; E. J. Broussals: Memoria sobre el cólera morbo epidémico observado y tratado en Paris... Madrid 1833; P. M. RuBio, L. SÁNCHEz NúNEEz, F. PAULA y FolCH: Informe General de la comisión facultativa enviada por el Gobierno español para observar el cólera morbo en paises extranjeros... Madrid 1834. 
de muertos pasados por los médicos a la Junta de Sanidad, y tratando de dar a los lectores la impresión de que la situación no era grave por el momento ${ }^{3}$.

El 17 de julio tuvo lugar en Madrid la matanza de frailes, tras rumorearse que ellos eran los responsables de la enfermedad por haber contaminado las aguas. En los días en que tuvieron lugar estos hechos violentos se temía por parte del Gobierno de la Reina Gobernadora que los progresos de la enfermedad, o un levantamiento impidieran la reunión de Cortes. En una Real Orden promulgada el día 18, siguiente al de la matanza, se dice: «La enfermedad que padece esta heróica villa ...ha sido el pretexto de tales excesos; y los enemigos del trono de Isabel II, de su Augusta Madre y de la justa libertad, la verdadera causa..." ${ }^{4}$. El clima de violencia, habitual en la capital, debió agravarse en estas fechas, siendo tan numerosas las personas heridas por las calles en riñas y tumultos que el mismo día 17 se promulgó una Real Orden en la que ordenaba a los médicos y cirujanos que: «...antes de dar cuenta a las Justicias de los heridos curen a los que lo estuvieren de mano violenta o de casualidad...", aunque las denuncias continuaban siendo obligatorias, y se penaba su abstención con cárcel, multas e incluso destierro en casos de reincidencia ${ }^{5}$.

Madrid había sido tradicionalmente foco de atracción de toda clase de gentes y en especial desempleados de todo tipo que llegaban por cientos en épocas de crisis, pensando encontrar en ella un medio de vida. Esta inmigración pobre, desarraigada de sus lugares de origen, no encontraba fácilmente acomodó en la gran ciudad, donde la falta de trabajo, la carestía de la vivienda, etc. les forzaba muchas veces a pedir limosna, dormir en las calles y recurrir a los establecimientos de beneficencia cuando no al robo o a la pequeña delincuencia.

En esta ocasión, como ya había sucedido otras veces, las autoridades municipales publicaron varios bandos en los que se mandaba hacer

${ }^{3}$ En el Diario de Avisos de Madrid de estos primeros días de julio de 1834, se publican las medidas tomadas por si la epidemia llega a la capital, así como artículos en donde médicos e higienistas dan consejos para no contraer la enfermedad o cómo curarla, pero el tono general da a entender que las medidas son simples precauciones y que la epidemia aún no se ha manifestado en la capital. Contrasta esta actitud con los partes oficiales dados por los médicos a la Junta Municipal en los que desde el día 2 de julio se denuncian ya los casos de cólera habidos en Madrid. AVB 1, 490, 3.

${ }^{4}$ Real Orden 18 de julio de 1834.

${ }^{5}$ Real Orden 17 de julio de 1834. 
desaparecer a los mendigos de las calles de Madrid. Los pedigüeños, además de constituir un desagradable espectáculo, representaban un peligro potencial en los momentos delicados y desde que tuvo lugar el motín de Esquilache, en el que las masas populares fueron protagonistas de levantamientos en contra del poder real ${ }^{6}$, la Administración tenía muy en cuenta su presencia a la hora de intentar controlar las situaciones difíciles. En la etapa 1832-1834, las medidas tomadas en relación con los necesitados, ante la amenaza que suponía la epidemia y más adelante la inestabilidad política creada por la guerra, fueron aún más duras que en otras ocasiones, llegando a constituir una verdadera represión.

Los informes médicos sobre el cólera, insistían como norma preventiva en la necesidad de mejorar las condiciones de vida de las clases populares, así como en la erradicación de los focos de insalubridad que existieran en las ciudades.

En 1832, de acuerdo con los planes elaborados por la Junta de Sanidad de Madrid en su primera fase de trabajo, el Ayuntamiento propuso una serie de medidas higiénicas y sanitarias para prevenir la epidemia y si ésta llegara hacerle frente ${ }^{7}$. Los principales puntos contenidos en la propuesta eran los siguientes: Traslación de los muladares situados extramuros de la ciudad a puntos más distantes; destrucción de las «casuchas o barracas" que recibían el nombre de "tejares", por considerarlos guaridas de viciosos y holgazanes y nidos de inmundicia, así como un peligro en las circunstancias de una posible epidemia; como en la anterior medida podía objetarse el que se dejara sin vivienda a familias de menesterosos, se aclaraba que estas familias eran en su mayor parte "parásitas y forasteras" y no debian residir en la Corte según las leyes y órdenes vigentes y debían ser restituidos a sus pueblos de origen, descargándose así la población de muchos «individuos inútiles y perniciosos». La limpieza diaria, si fuese preciso de todas las calles y plazas; los vecinos debian depositar las basuras en medio del arroyo para ser barridas; la creación de servicios públicos en las calles para evitar «...la asquerosidad que hoy se observa no sólo en las calles excusadas sino en muchas principales y en los portales de las casas»; prohibición de criar gallinas ni ningún otro animal doméstico en los patios de las casas; los

\footnotetext{
${ }^{6}$ Sobre este punto puede consultarse P. VILAR: «El Motín de Esquilache y las crisis del Antiguo Régimen", Revista de occidente, núm. 107.

7 «Medidas Sanitarias propuestas por el Ayuntamiento». Diario de Avisos de Madrid, 2 de mayo de 1832
} 
puestos de venta de pescado, frutas y verduras debían situarse en los arrabales y estar limpios y controlados; evitar las basuras y animales muertos y aguas corrompidas en las calles; la reforma de las posadas llamadas "de pobres", que si bien no se prohibieron de forma absoluta sí se introdujo en ellas una policía rigurosa que hiciera cumplir unas ciertas ordenanzas; la limpieza de alcantarillas, con abundante vertido de aguas limpias y control para no dejar estancar las aguas residuales, así como la quema de maderas aromáticas para evitar la fetidez de los sumideros; por último se llamaba la atención sobre las viviendas en las que vivían hacinados - hasta 20 ó 30 individuos en un solo cuarto- los aguadores y mozos de cordel, aunque no se determinaba nada sobre este punto.

Para el caso de que la enfermedad llegara a manifestarse se proponía: crear hospitales para los enfermos que carecieran de recursos, en los edificios que se considerara oportuno - en 1834 se habilitó con este fin la casa llamada de Durán, y el Hospital del Saladero-; también casas de socorro - fueron creadas 11 distribuidas por todo Madrid, y realizaron la labor de hospitales provisionales-; matrícula rigurosa de los médicos existentes en la Capital; limpieza de cuartelas, casas de reclusión, hospitales, etc.; abrir suscripciones, y pedir a los ciudadanos limosnas para contribuir junto con el Ayuntamiento a todos los gastos producidos por la epidemia; obras de alcantarillado; observancia rigurosa en la sanidad de los alimentos y por último realizar una «matrícula rigurosa» de todos los pobres existentes en la capital, para determinar cuáles debían de ser expulsados a sus lugares de origen y cuáles recluidos o internados en centros de beneficencia. Los que no tuvieran trabajo, y llevaran menos de 10 años de residencia en la capital serían enviados a sus pueblos, dándoles un pasaporte, una peseta y dos panes.

La mayor parte de estas propuestas se llevó a la práctica de forma gradual. Las últimas en llevarse a efecto fueron las referentes a creación de casas de socorro, habilitación del Hospital del Saladero, y petición de limosnas y suscripciones a la población para ayudar en los gastos ocasionados por la epidemia. Desde los primeros días del mes de julio de 1834, en el Diario de Avisos de Madrid se va dando noticias a los vecinos sobre estos centros recién creados a los que pueden dirigirse en caso de enfermedad. Se habilitan también por Real Orden los hospitales privados para que atiendan a toda clase de enfermos ${ }^{8}$.

\footnotetext{
${ }^{8}$ Real Orden 30 de julio de 1834.
} 
No sabemos cuántos fueron los pobres que el Ayuntamiento hizó salir de Madrid entre 1832 y 1834 pero sí conocemos la cantidad gastada en su desplazamiento que fue de 61.800 reales $^{9}$. Aquellos que por ser naturales de la capital, de buena conducta y estar impedidos para trabajar fueran huérfanos o viudos fueron recogidos en agosto de 1834, tras realizar un padrón de los existentes en cada barrio que fue encargado por el Corregidor de la Villa a cada una de las 62 diputaciones existentes ${ }^{10}$. Suponemos que los considerados "vagamundos" o pobres actos para realizar trabajo serían recluidos en la cárcel, destinados a obras públicas o enviados a servir en barcos o cuarteles como era costumbre. La medida dio lugar a un amplio expediente donde quedan detallados todos los pasos dados para recluir a los pobres ${ }^{11}$. La Junta General de Caridad intentó en primer lugar recluirlos en la Casa de Beneficencia. Eran en esta ocasión un total de 351 entre hombres y mujeres. Para ello se llegó a un acuerdo con el director de la Casa, que pedía se le pagara por anticipado un mes de la estancia de los pobres, cobrando por cada uno 2 reales y medio. La financiación de tal operación corría a cargo de la suma reunida en el Banco de San Fernando, procedente de suscripciones y limosnas de particulares, donativos hechos por el Colector General de Expolios y el Comisario General de Cruzada, y fondos aportados por el Ayuntamiento de diversos impuestos. Esta cantidad era administrada por la Junta de Sanidad de Madrid. En el último momento, y sin mediar explicación por parte de ninguna de las instituciones implicadas, se creó por Real Orden de 3 de agosto de 1834 el Asilo de mendicidad en el que hasta esos momentos había sido Convento de San Bernardino. Este Asilo llegaría a ser uno de los más importantes depósitos de pobres del Madrid del siglo XIX, financiado por la caridad privada, que proporcionaba fondos por medio de suscripciones mensuales. Más tarde pasaría a cargo del Ayuntamiento.

En la Guía de Forasteros de 1836 - su información se refiere a todo el año 1835- se dice del Asilo: «Este establecimiento... que en su origen se hallaba sin más recursos que un lugar mezquino y mal proporcionado ha llegado en un solo año de existencia a reunir más de 6.000 pobres de los cuales hay en el día 725 , los demás han sido despachados socorridos al pueblo de su respectiva naturaleza, por carecer de las circuns-

${ }^{9}$ Cuentas de la Tesorería de la Villa. AVC 1, 450, 32.

${ }^{10}$ Con fecha 5 de mayo de 1834 el Corregidor ordena a todas las Diputaciones de Caridad que realicen un padrón de los pobres que existen en el barrio. Libro Actas P. San Nicolás. AVC 1, 93, 40. fol. $18 \mathrm{v}$.

${ }^{11}$ Expediente para recluir a 351 pobres. $\operatorname{AVC} 3,375,19$. 
tancias que se fijaron en el reglamento provisional». Por tanto, en el año que siguió al de la epidemia fueron de nuevo expulsados alrededor de 5.000 forasteros sin recursos de Madrid ${ }^{12}$.

Las medidas higiénicas tomadas por el Ayuntamiento, suponían sin duda una mejora muy apreciable en las condiciones de vida de la capital, pero no ofrecían una alternativa para elevar las condiciones de las clases populares, sino que constituian una verdadera represión para los forasteros necesitados, obligándoles a volver a sus lugares de origen o a recluyéndoles en las casas de beneficencia. Este enfoque del problema nos muestra la mentalidad de la clase dirigente de estos años frente al tema de la pobreza.

En el informe rendido por Junta de Sanidad de Madrid en contestación a la Real Orden de 22 de enero de 1835, queda claramente expuesta la labor conjunta realizada por ambas corporaciones, el número de enfermos asistidos y fallecidos, las ayudas prestadas, etc. ${ }^{13}$. Además de la creación de casas de socorro y puesta en marcha de hospitales provisionales, la Junta General de Caridad, a través de las Diputaciones de Barrio, fomentó la ya practicada hospitalidad domiciliaria, ordenando la creación de una guardia permanente en cada Diputación para ayudar a los enfermos que se presentasen y la contratación de médicos y cirujanos para ampliar la plantilla de los que ya trabajaban en éstas durante la epidemia. Para financiar la operación, la Junta libró 1.500 reales a cada Diputación, además de promover en cada una de ellas las suscripciones y limosnas entre los vecinos. Según su situación en barrios ricos o pobres las Diputaciones tuvieron más o menos limonas y más o menos enfermos que atender. Por ello, algunas pudieron devolver a la Junta General de Caridad el dinero que no habían gastado una vez terminada la epidemia ${ }^{14}$, otras en cambio, se vieron en la necesidad de pedir más fondos para poder atender a los enfermos.

La epidemia se cebó entre los más pobres; murieron un total de 4.463 personas ${ }^{15}$ siendo las parroquias que más muertos contabilizaron

${ }^{12}$ En 1834 según el informe de la Junta de Sanidad de Madrid, había en la capital una población de 220.000 habitantes. Esta cifra puede servirnos de referencia para apreciar la importancia de la expulsión de forasteros pobres que tuvo lugar entre 1832 y 1834. Informe de la Junta de Sanidad de Madrid. Enero 1834. AVC 3, 358, 46.

${ }^{13}$ Idem.

${ }^{14}$ Cuentas rendidas por las Diputaciones de Barrio a la Junta General de Caridad en 1835. AVC 375, 113.

${ }^{15}$ Doc. cit. (12) AVC 3, 358, 46. 
las situadas en los barrios habitados por gentes de las clases populares. En primer lugar se encontraba la parroquia de San Martín, con 887 muertos, en segundo San Luis, con 418, en tercero San José, con 390, y en cuarto San Sebastián, con 325. Contrastan con las situadas en los barrios aristocráticos, como Santa María con 29 muertos y Santiago y San Salvador con 13 cada una ${ }^{16}$.

Las Diputaciones de Barrio se encargaron también de recoger a los niños cuyos padres habían fallecido en la epidemia; más tarde, la Junta General de Caridad les buscó lugar donde alojarles. Según su edad, unos fueron recogidos en la Inclusa y otros en la Casa de Beneficencia. El total de niños que quedaron huérfanos fue de 90 , siendo ingresados en los establecimientos mencionados 35 , quedando los demás al cuidado de familiares o amigos ${ }^{17}$.

No es posible conocer el alcance total de la caridad privada en esta ocasión, ya que no todas las limosnas fueron contabilizadas. Sabemos que las cantidades ingresadas en concepto de limosnas y suscripciones en el Banco de San Fernando fue de 355.190 reales en los meses que duró la epidemia ${ }^{18}$. No sabemos el total de lo recaudado por las Diputaciones de Barrio ${ }^{19}$. Otros ejemplos conocidos son la cantidad de 10.000 reales dada de forma extraordinaria a los pobres por la Parroquia de San Sebastián durante el mes de julio ${ }^{20}$, o las cantidades consignadas en las cuentas anuales de la Hermandad del Refugio que fueron 52.217 reales gastados en el socorro domiciliario a 3.669 pobres aproximadamente, 1.000 personas más socorridas durante el año 1834, que en el año anterior y posterior. También la cantidad de 7.704 reales en cenas para los pobres ${ }^{21}$. Es de suponer que otras asociaciones de beneficencia darian también limosnas excepcionales durante la epidemia, pero no conocemos estos datos.

La situación creada por el cólera de 1834 afectó de forma especialmente negativa a los sectores más pobres de la sociedad, ya que además de contraer la enfermedad con mayor facilidad por estar depauperados, y vivir en malas condiciones higiénicas, tuvieron que sufrir

\footnotetext{
${ }^{16}$ Idem.

17 Expediente para la recogida de huérfanos. $A V B$ 1, 236, 12.

${ }_{18}$ Doc. cit. (12) $A V C$ 3, 358, 46.

19 Doc. cit. (12) $A V C$ 3, 375, 113.

${ }^{20}$ Actas Parroquia San Sebastián, julio 1834. AVB 1, 246, 1.

21 Guía de Forasteros. Madrid, Imprenta Nacional, 1836. Pág. 235.
} 
una dura represión desencadenada por las autoridades que veían en los pobres y mendigos un peligro potencial de revueltas, y levantamientos contra el régimen establecido.

Como consecuencia positiva, además de las medidas asistenciales desarrolladas para atender a los necesitados, quedaron la creación del Asilo de San Bernardino, donde más tarde se crearían talleres para formar y dar oficio a los necesitados acogidos y el precedente para las casas de socorro, que se establecerían de forma permanente en todos los distritos madrileños a partir de 1859. 